\title{
Higher-Order Terms in Bivariate Returns to International Stock Market Indices
}

\author{
Kirt C. Butler \\ Michigan State University, U.S.A. \\ Katsushi Okada \\ Michigan State University, U.S.A.
}

This article documents the stochastic properties of bivariate returns to international stock market indices. In particular, the article searches for the best fit among a class of higher-order $\operatorname{VARMA}(u, v)-\operatorname{EGARCH}(p, q)$ models with normal errors and a constant conditional correlation using MSCI domestic and world-ex-domestic index pairs for the Emu, Japan, the United Kingdom, and the United States. Although a first-order VAR or VMA specification is sufficient to accommodate the conditional means, second-order EGARCH terms are necessary in two of the four bivariate series (JEL: G15 G11 C15 C34).

Keywords: higher-order, bivariate, international diversification, EGARCH, VARMA.

\section{Introduction}

This article examines the stochastic properties of bivariate daily returns to the MSCI domestic and world-ex-domestic stock market index pairs for the Emu, Japan, the United Kingdom, and the United States. In particular, the article examines whether higher-order terms are necessary in these series by searching for the best fit among the class of bivariate $\operatorname{VARMA}(u, v)$-EGARCH$(p, q)$ models with a constant conditional correlation and normally distributed errors using conditional mean and volatility terms at lags of up to three days. First-order terms are usually sufficient to capture the conditional mean and volatility of univariate price series (Engle [1993]). First-order models have a more straightforward economic interpretation than higher-order models, and are easier to construct (He, Teräsvirta and Malmsten [2002]) and econometrically

* The authors thank an anonymous referee for thoughtful and constructive comments.

(Multinational Finance Journal, 2008, vol. 12, no. 1/2, pp. 127-155)

Quarterly publication of the Multinational Finance Society, a nonprofit corporation.

(C) Global Business Publications. All rights reserved.

DOI: $10.17578 / 12-1 / 2-6$ 
more tractable (He and Teräsvirta [1999]). The suitability of first-order models for bivariate returns to international indices has not been investigated. Higher-order terms could arise for many reasons, including technical factors such as nonsynchronous measurement of returns (Lo and MacKinlay [1990]) or behavioral factors (Hirshleifer [2001]) such as market contagion (Bae, Karolyi and Stulz [2003]).

Higher-order conditional volatility terms are significant in half of these bivariate series. This is about the same proportion as in the univariate series. Although an $\operatorname{EGARCH}(1,1)$ model provides a relatively good fit for bivariate U.K. and U.S. returns, second-order EGARCH terms are useful in the Emu and Japan series. The additional terms have significant coefficients and yield improved residual behaviors and significant robust Wald statistics relative to the EGARCH $(1,1)$ model. The conditional means of these bivariate series can be modeled equally well with first-order vector autoregressive (VAR) or moving average (VMA) terms.

\section{Data}

In order to take the perspective of a domestic investor considering the diversification benefits of international assets, Morgan Stanley Capital International (MSCI) value-weighted domestic and world-ex-domestic (world return excluding domestic return) stock market indices are employed for the Emu, Japan, the United Kingdom, and the United States. This contrasts with most studies of international returns, which study correlations between national markets. The bivariate distribution of domestic/world-ex-domestic returns is important because it determines the diversification gains to domestic investors from international investments.

The model is estimated using continuously compounded local currency daily returns to MSCI official price indices for the domestic Emu, Japanese, U.K. and U.S. markets and their corresponding world-ex-domestic indices over the period 02/01/1996 through $12 / 31 / 2002$. These four domestic markets account for about 90 percent of total MSCI stock market capitalization. Local currency returns are used to represent returns earned by domestic investors that are fully hedged against currency risk. As a practical matter, the stochastic properties of local currency and U.S. dollar returns are quite similar.

Some days in the sample period, such as national holidays, have a zero (missing) return for a domestic index and a non-zero return for the 
corresponding world-ex-domestic index. To preserve the continuity of the bivariate series, non-trading days in each domestic market are aggregated onto the next trading day in that market. Returns to the world-ex-domestic index over these periods are similarly aggregated into a single return so that the world-ex-domestic sample aligns with the domestic index. This convention preserves the perspective of a domestic investor, for whom non-trading days in the domestic market have volatilities that are only a small fraction of the volatilities on trading days (French and Roll [1986]).

Descriptive statistics for each series appear in table 1. Significant skewness and kurtosis indicate that these observed daily returns are not normally distributed. Seven out of eight skewness measures are negative because of a few large negative returns, and five are significant at 5 percent. All eight univariate indices are leptokurtic and significant at 1 percent. These nonnormalities guide the choice of an EGARCH specification to accommodate volatility asymmetry, as well as a robust quasi-maximum likelihood estimation technique in Section III.

Significant first-order autocorrelation is present at one percent in each of the world-ex-domestic indices and at five percent in the Emu index, presumably because the national markets comprising these indices close at different times throughout the day. Six of the eight univariate indices exhibit at least one significant second-order or third-order partial autocorrelation, indicating that price-adjustment delays last longer than one day in these data.

The serial cross correlations reflect the closing times of the various domestic and world-ex-domestic markets. Japan is the first market to open and the United States is the last to close during each calendar day. Thus, observed returns in Japan should be related to the previous day's world-ex-Japan returns and observed U.S. returns should be related to the next day's world-ex-U.S. returns. In table 1, first-order cross correlation is indeed significant at 1 percent when the Emu (0.2062), Japanese (0.3103), or U.K. (0.1821) index lags the corresponding world-ex-domestic index. The first-order cross correlation between the Japanese index and the corresponding world-ex-Japan index (0.3103) actually exceeds the contemporaneous correlation (0.1743). First-order serial cross correlation is only significant for the U.S. index when it is paired with the next day's world-ex-U.S. index (0.4006). Higher-order serial cross correlations are insignificant, with the exceptions of two third-order U.K. and one Emu serial cross correlations. Partial autocorrelations and serial cross correlations at lags greater than three are not significant in these data. 


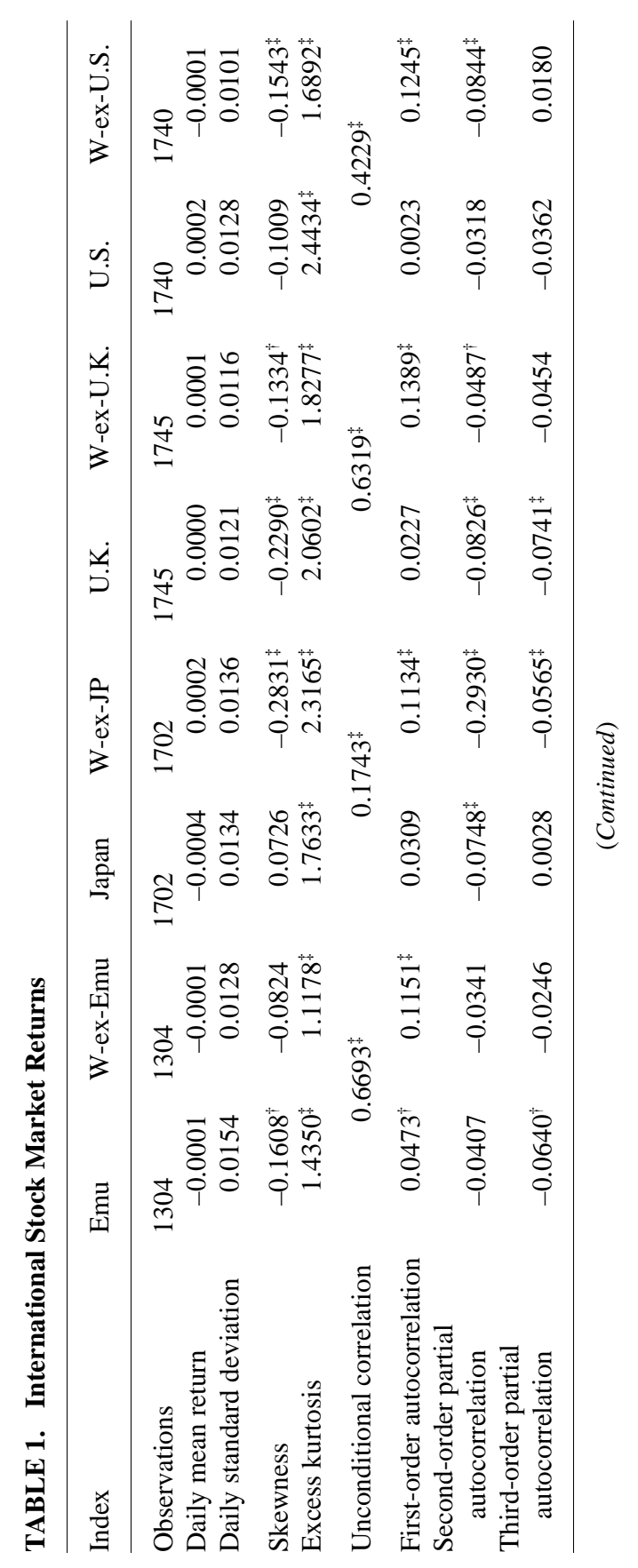




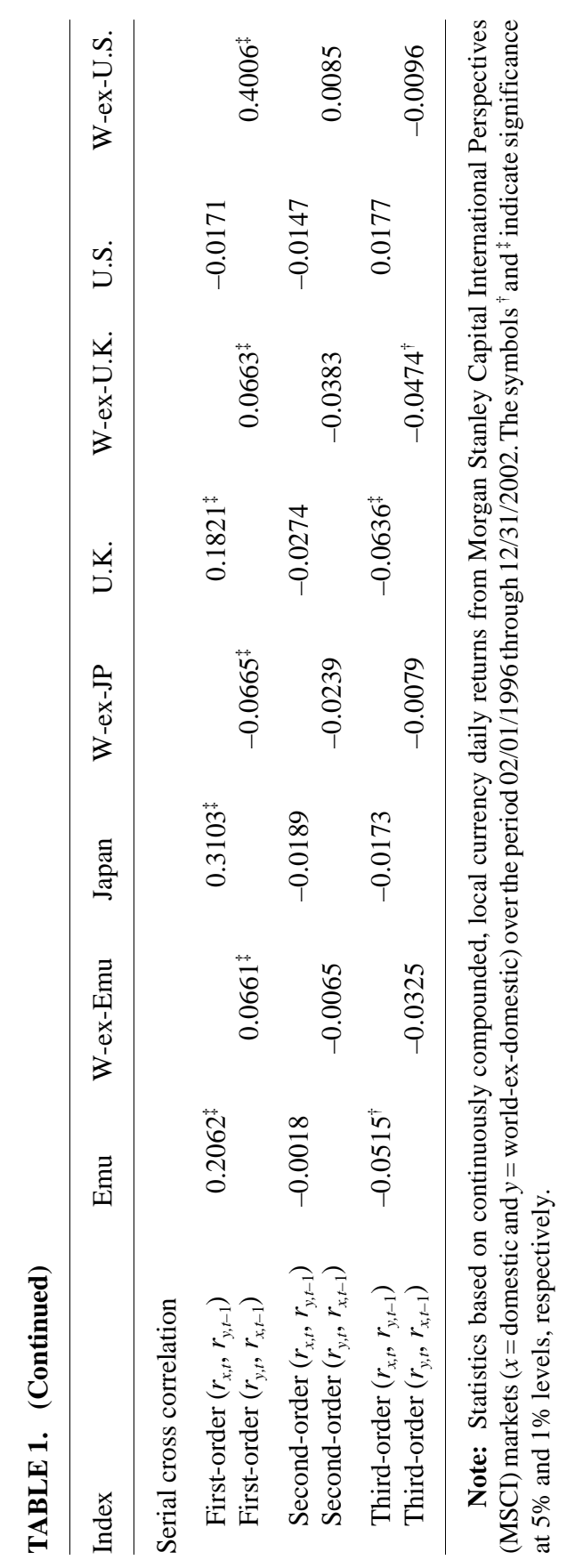




\section{The Model}

A bivariate $\operatorname{VARMA}(u, v)$-EGARCH$(p, q)$ model with a constant conditional correlation and normally distributed errors is adopted using conditional mean and volatility terms of up to three lags. This class of models is a tractable and parsimonious way to produce unconditional return distributions that fit the characteristics of observed returns to international stock indices, including significant autocorrelations and serial cross correlations at higher-order lags, time-varying means and volatilities, and asymmetric conditional volatility with relatively high comovements in the lower tails of return. The assumptions of a constant conditional correlation and normally distributed errors are popular because they are conceptually simple and computationally convenient. VARMA-in-mean terms describe the linear relation of index returns to recent returns and volatilities in that and another index.

Nelson's (1991) EGARCH model is a popular choice for modeling volatility asymmetry in univariate returns in which volatility tends to increase in response to bad news (Black [1976]; Christie [1982]; Cheung and Ng [1992]). ${ }^{1}$ Comparisons have favored EGARCH over competing models for stock index returns in the U.S. (Pagan and Schwert [1990]; Kim and Kon [1994]; and Chen and Kuan [2002]), and Japan (Engle and Ng [1993]), emerging markets (Chong, Ahmad amd Abdullah [1999]), and small stocks (Cao and Tsay [1992]). EGARCH also has had success in modeling the implied option volatilities of stock indices (Day and Lewis [1992]).

Bivariate EGARCH has been successful in capturing interactions between an international stock index and another stock index (Koutmos, Negakis and Theodossiou [1993]; Koutmos [1996]; Booth, Martikainen and Tse [1997]; Christofi and Pericli [1999]; and Niarchos, et al. [1999]), exchange rates (Koutmos [2000]), interest rates [Lobo (2000]), and financial market liberalizations (Kassimatis [2002]); and between interest rate futures prices (Cheung and Fung [1997]; Tse and Booth [1996]; and Tse [1998]) and volumes (Jacobs and Onochie [1998]).

1. Alternatives to EGARCH for modeling asymmetric conditional volatility include (Glosten, Jaganathan and Runkle [1993]; Rabemananjara and Zakoian [1993]; and Hentschel [1995]), contemporaneous asymmetry models (Babsiri and Zakoian [2001]), stochastic volatility models (Wu [2001]), and regime-switching models (Hamilton [1989]; Fornari and Mele [1997]; and Ang and Bekaert [2002]). The EGARCH model has itself been extended in a number of ways, such as fractionally integrated EGARCH (Bollerslev and Mikkelsen [1996] and Baillie, Cecen and Han [2000]) and switching EGARCH (Daouk and Guo [2002]). 


\section{A. A Univariate MA(1)-EGARCH(1,1) Baseline}

Estimation results based on bivariate models indicate that first-order VMA(1) or VAR(1) terms are sufficient for modeling the conditional means, but that second-order terms can be beneficial in the conditional volatilities. Moreover, ARCH-in-mean terms are not significant in the univariate series. Consequently, MA(1)-EGARCH(1,1) and MA(1)$\operatorname{EGARCH}(2,2)$ models are estimated for each index as baselines for evaluating the bivariate models:

$$
\begin{gathered}
r_{t}=a_{0}+m_{1} \varepsilon_{t-1}+\varepsilon_{t} \\
\ln h_{t}=\omega_{0}+\omega_{1} \ln h_{t-1}+\omega_{2} \ln h_{t-2}+\lambda_{1} g_{t-1}+\lambda_{2} g_{t-2}
\end{gathered}
$$

where the $g_{t}=\gamma z_{t}+\left|z_{t}\right|-E\left|z_{t}\right|$ term captures the asymmetric effects of positive and negative shocks on conditional volatility. Innovations $\varepsilon_{t}$ are assumed to be normally distributed, such that $\varepsilon_{t} \sim N\left(0, h_{t}\right)$ and $z_{t}=\varepsilon_{t} / \sqrt{ } h_{t} \sim N(0,1)$.

Parameters are jointly estimated by maximum likelihood using the $B F G S$ method. Maximizing a Gaussian log-likelihood function under nonnormality yields consistent estimators called quasi-maximum likelihood ( $Q M L E)$ estimators even if the residuals are not normal (White [1982]). For testing $Q M L E$ estimators $\hat{\Psi}_{t}$, the variancecovariance matrix must be adjusted as:

$$
\operatorname{Var}\left(\hat{\Psi}_{t}\right)=\frac{1}{T}\left(\hat{C}_{t}^{-1} \hat{D}_{t} \hat{C}_{t}^{-1}\right)
$$

where $\hat{\mathrm{C}}_{t}=-(1 / \mathrm{T}) \sum_{t=1}^{T} \mathrm{Z}_{\mathrm{t}}\left(\hat{\Psi}_{t}\right), \hat{D}_{t},=-(1 / \mathrm{T}) \sum_{t=1}^{T} \Delta_{t}\left(\hat{\Psi}_{t}\right)^{\prime} \Delta_{t}\left(\hat{\Psi}_{t}\right)$, $\Delta_{t}(\bullet)$ is the outer product gradient vector and $Z_{t}(\bullet)$ is the Hessian matrix of the $\log$-likelihood function at time $t$, and $T$ is the number of observations in the sample.

\section{B. The Bivariate VARMA(u,v)-EGARCH $(p, q)$ Models}

Several versions of a bivariate $\operatorname{EGARCH}(p, q)-M$ with $\operatorname{VARMA}(u, v)$-in -the-mean model for a domestic market $x$ and a world-ex-domestic market $y$ are considered,

$$
\begin{gathered}
R_{t}=A_{0}+\sum_{u} A_{u} R_{t-u}+\sum_{v} M_{v} E_{t-v}+\Theta H_{t}+E_{t} \\
\text { and } \ln H_{t}=\Omega_{0}+\sum_{p} \Omega_{p} \ln H_{t-p}+\sum_{q} \Lambda_{q} G_{t-q}
\end{gathered}
$$


for $u, v, p$ and $q$ up to three lags, domestic ( $x$ ) and world-ex-domestic (y) returns $R_{t}=\left[r_{x, t} r_{y, t}\right]^{\prime}$, innovations $E_{t}=\left[\varepsilon_{x, t} \varepsilon_{y, t}\right]$ ' such that $\varepsilon_{t} \sim N\left(0, h_{t}\right)$ for each index, autoregressive conditional $\log$ volatility vector $\left(\ln H_{t}\right)=[\ln$ $\left.h_{x, t} \ln h_{y, t}\right]^{\prime}$, moving average volatility vector $G_{t-1}=\left[g_{x, t-1} g_{y, t-1}\right]^{\prime}$ such that $g_{t}=\gamma z_{t}+\left|z_{t}\right|-E\left[\left|z_{t}\right|\right]$ for $z_{t}=\varepsilon_{t} / \sqrt{ } h_{t} \sim N(0,1)$ for each index, and ARCH-in-mean effects $\Theta H_{t}$. The remaining terms are parameter matrices of the appropriate order. Following Bollerslev (1990), we assume conditional covariance is given by:

$$
h_{x y, t}=\rho_{x y}\left(\sqrt{h_{x, t}}\right)\left(\sqrt{h_{y, t}}\right)
$$

where $\rho_{x y}$ is the constant conditional correlation between $r_{x}$ and $r_{y}$.

\section{Diagnostics}

Ljung-Box (1978) $Q$ statistics assess the goodness-of-fit of alternative $\operatorname{VARMA}(u, v)$ conditional mean specifications. The Ljung-Box $Q$ statistic is defined by:

$$
Q_{L}=T(T+2) \sum_{k=1}^{L} \frac{\rho_{x y, k}^{2}}{T-k},
$$

where $\rho_{x y, k}^{2}$ are squared sample auto- or serial cross correlations at lags from $k=1$ to $L$. For a bivariate series, the $Q_{L}$ statistic is asymptotically chi-square distributed with $2^{2}[L-(u+v)]$ degrees of freedom under the null hypothesis that a particular model is well specified.

Hosking (1980) extends the $Q$-statistic to multivariate models. In the case of a bivariate model with a maximum lag $L$, the multivariate portmanteau statistic is defined by:

$$
P_{L}=T(T+2) \sum_{k=1}^{L} \frac{1}{(T-k)} \operatorname{Trace}\left[\hat{C}_{0 k} \hat{C}_{00}^{-1} \hat{C}_{00}^{\prime} \hat{C}_{0 k}^{-1}\right]
$$

where

$$
\hat{C}_{0 k}=T^{-1} \sum_{t=k+1}^{T}\left(\hat{E}_{t} \hat{E}_{t-k}^{\prime}\right)
$$

For a bivariate series, Hosking's portmanteau statistic is asymptotically chi-square distributed with degrees of freedom $2^{2}[L-(u+v)]$ under the 
null hypothesis that the residuals are white noise. A rejection indicates that at least one of the two bivariate series is not white noise. We chose $L=20$ after investigating various lags for the $P$ and $Q$ statistics.

Engle and Ng's (1993) joint bias test statistic is used to detect misspecifications related to asymmetries in the conditional volatilities. This statistic examines whether squared normalized residuals can be predicted by observed variables that are not included in the model:

$$
\hat{\varepsilon}_{t}^{2}=\varphi_{0}+\varphi_{1} w_{t-1}^{-}+\varphi_{2} w_{t-1}^{-} \hat{\varepsilon}_{t-1}+\varphi_{3}\left(1-w_{t-1}^{-}\right) \hat{\varepsilon}_{t-1}+e_{t}
$$

where $w_{t-1}^{-}$is a dummy variable that takes the value 1 when the residual $\hat{\varepsilon}_{t-1}$ is negative and 0 when positive. This joint bias test combines Engle and Ng's sign bias $\left(\varphi_{1} w_{t-1}^{-}\right)$, negative size bias $\left(\varphi_{2} w_{t-1}^{-} \hat{\varepsilon}_{t-1}\right)$, and positive size bias $\left(\varphi_{3}\left(1-w_{t-1}^{-}\right) \hat{\varepsilon}_{t-1}\right)$ tests into a single nonparametric statistic. The null hypothesis $H_{0}: \varphi_{0}=\varphi_{1}=\varphi_{2}=\varphi_{3}=0$ is evaluated with the test statistic $T R^{2}$ from this regression, which is asymptotically chi-square distributed with three degrees of freedom. If any of the $\varphi_{i}$ are significant based on a one-tailed test, then equation 3 is not fully predicting the effect of the shock at time $t-1$ on the conditional variance at time $t$.

Engle's (1982) $L M_{L}$ statistic tests for $\operatorname{ARCH}(L)$ disturbances in the residuals. $L M_{L}$ statistics are calculated by regressing squared standardized residuals on a constant and $L$ lagged values of the squared residuals. The $L M_{L}$ test statistic is calculated from the adjusted $R^{2}$ of this regression, $(T-L) R^{2}$, and is asymptotically chi-square distributed with $L$ degrees of freedom. A lag of 4 is chosen for the $L M$ statistic because the models have at most third-order terms. If $L M_{4}$ is significant based on a one-tailed test, then the model is not fully predicting the effects of shocks at times $t-L$ through $t-1$ on the conditional variance at time $t$.

For the final model, some additional tests are applied to the conditional volatility specification. $L M_{L}$ statistics at lags of $L=2,3$, and 4 test the various EGARCH specifications. $Q_{20}^{2}$ statistics of the conditional mean specification based on $20^{\text {th }}$-order autocorrelation in the squared standardized residuals test for volatility clustering in the final model. $Q_{L}^{2}$ statistics are simply $Q_{L}$ statistics applied to squared standardized residuals and are asymptotically chi-square distributed with $2^{2}[L-(u+v)]$ degrees of freedom.

A robust Wald (1943) test is conducted to see if the VARMA and EGARCH coefficients of order higher than 1 are jointly significant. To 


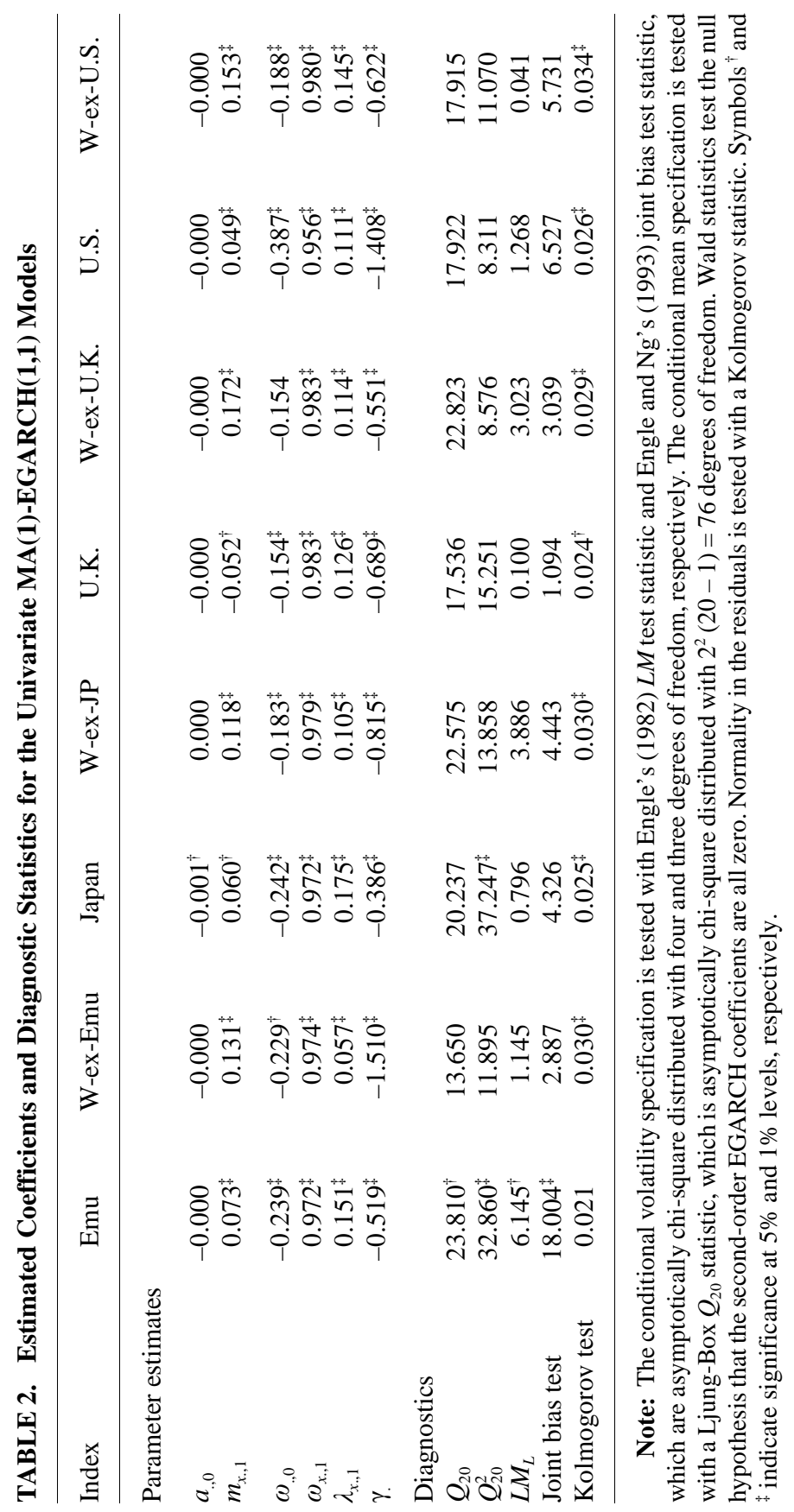


test the quasi-maximum likelihood parameter estimates $\hat{\theta}$ against restrictions $\theta_{0}$, note that $T^{1 / 2}\left(\theta=\theta_{0}\right)$ is asymptotically normally distributed under the null hypothesis. Squaring this and dividing by the variance of the estimate $\hat{\theta}$ yields a robust Wald statistic,

$$
W=\left(\hat{\theta}-\theta_{0}\right)^{2} / \operatorname{var}(\hat{\theta})
$$

that is asymptotically chi-square distributed with degrees of freedom equal to the number of restrictions being tested. A significant Wald statistic implies that higher-order coefficients are jointly significant, and that omitting them is likely to cause biased estimation.

Finally, bivariate normality in the residuals from the final models are tested with a Kolmogorov test on the univariate residuals and Mardia's skewness and kurtosis tests on the bivariate residuals. Residuals should be able to pass these normality tests if the VARMA-EGARCH model with normally distributed errors is well specified.

\section{Estimation Results}

\section{A. A Univariate Baseline for the Higher-order Terms}

An MA(1)-EGARCH $(1,1)$ model is first estimated as a baseline for evaluating the bivariate series. The choice between an $\mathrm{AR}(1)$ and an MA(1) conditional mean specification was not critical, as each was able to account for the conditional means. Higher-order conditional mean terms were not significant and didn't improve model performance.

Table 2 reports parameter estimates and diagnostic statistics for the MA(1)-EGARCH(1,1) model. All of the parameter estimates are significant, with the exception of a few constant terms. The persistence parameters $\omega_{x, 1}$ range from 0.956 to 0.983 , and the news impact parameters $\lambda_{x, 1}$ range from 0.057 to 0.175 . EGARCH is preferred to $\mathrm{GARCH}$, as the EGARCH asymmetry term $\gamma$ is negative and significant in each series. Although each of the series except the Emu has non-normal residuals, the remaining diagnostic tests reveal very few other problems. The Emu series is the exception, with poorly behaved but relatively normal residuals.

Table 3 reports estimates and diagnostic statistics for each of the 


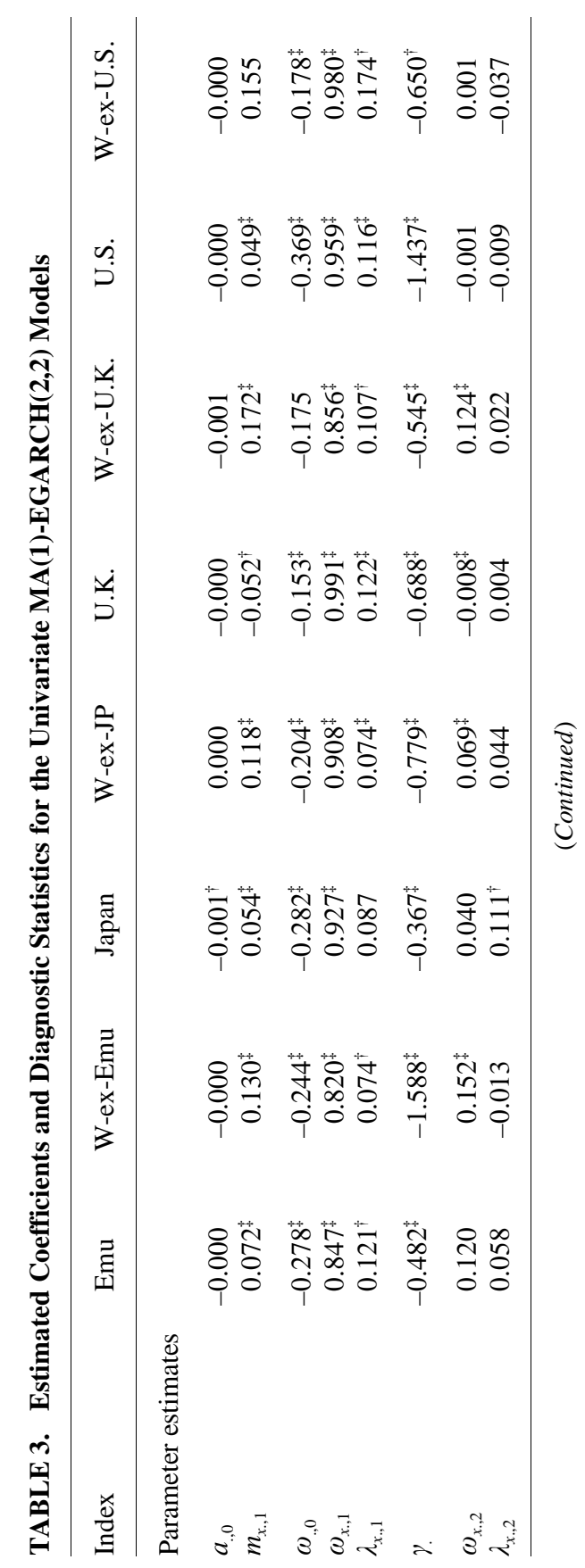




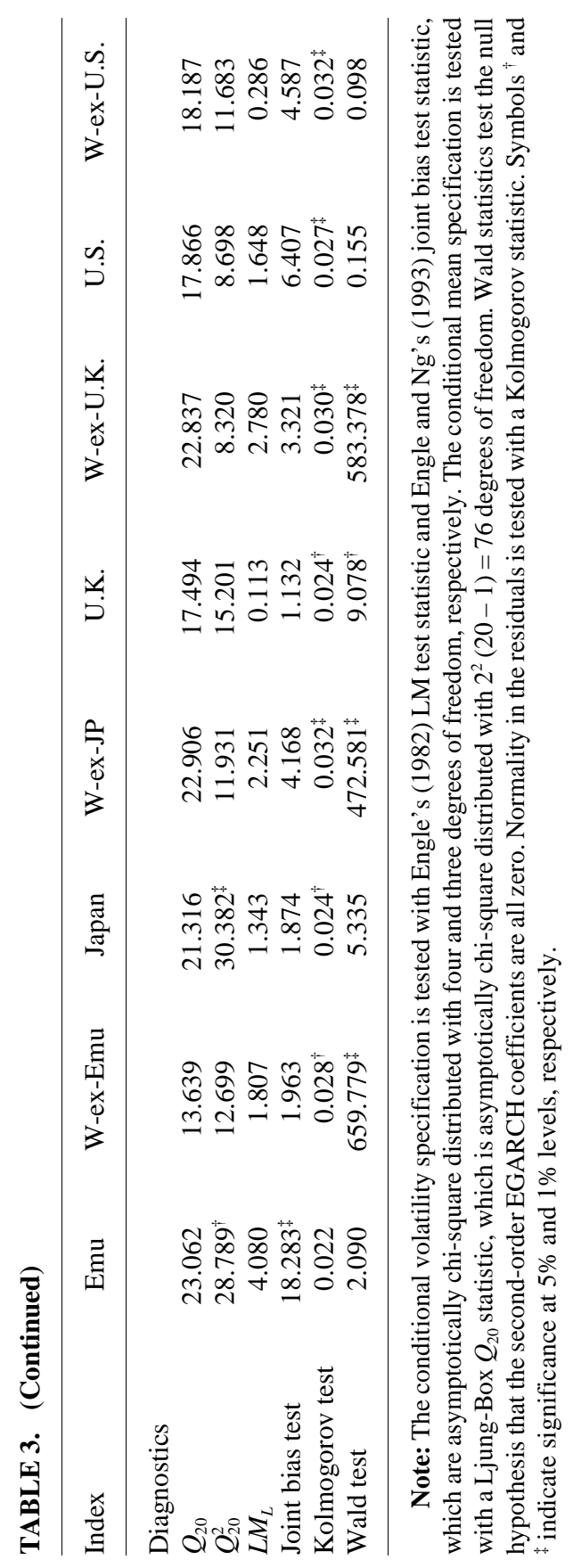


univariate series using an $\mathrm{MA}(1)-\operatorname{EGARCH}(2,2)$ model. Adding second-order conditional volatility terms yields four significant persistence parameters $\omega_{x, 2}$ and one significant news impact parameter $\lambda_{x, 2}$. The four series that have significant $\omega_{x, 2}$ terms also have significant robust Wald statistics. The residual behaviors of the second-order models are similar to those from the first-order models. As with the second-order model, the Emu is the only series that does not pass the diagnostic tests.

\section{B. Higher-order Terms in the Bivariate Series}

The partial autocorrelations and serial cross correlations in table 1 suggest that coefficients on the lagged $A R_{t-1}$. and $M E_{t-1}$ terms are likely to be important, and that the importance of these terms may differ across market pairs. An exhaustive search through the class of $\operatorname{VARMA}(u, v)$-EGARCH$(p, q)$ models for arbitrary lags 0 through $L$ would include $(L+1)^{4}$ distinct model specifications. For a maximum lag of $L=3$, this would include $(3+1)^{4}=256$ model estimations.

To reduce the search space, assume that the conditional mean and conditional volatility structures are independent beyond one lag and insignificant beyond three lags. This allows a separate search through the set of VARMA $(u, v)-\operatorname{EGARCH}(1,1)$ and $\operatorname{VARMA}(1,1)-\operatorname{EGARCH}(p, q)$ models using a maximum lag of 3 . This assumption reduces the search space to $2(3+1)^{2}=32$ model specifications. Diagnostic statistics for $\operatorname{VARMA}(0,0)$ and $\operatorname{EGARCH}(0,0)$ models are reported as a baseline. Diagnostic statistics reject these unconditional models at a 1 percent significance level in each case.

A search is conducted for the most parsimonious model with insignificant probability values ( $p$-values) on the diagnostic statistics, imposing this criterion separately for the EGARCH and VARMA searches. In particular, a search is conducted for the most parsimonious $\operatorname{VARMA}(1,1)$-EGARCH $(p, q)$ model according to the $p$-values of the $\mathrm{LM}_{4}$ and joint bias statistics across the various EGARCH specifications. Another search is then conducted for the most parsimonious $\operatorname{VARMA}(u, \mathrm{v})$-EGARCH $(1,1)$ model that minimizes the maximum misspecification in the $p$-values of the $Q_{20}$ and $P_{20}$ statistics.

Wald statistics are calculated relative to the first-order model in each variable. Models with lags greater than $(1,1)$ are compared to the $(1,1)$ model. Models with only a $p$ or $u$ term are compared to a $(1,0)$ baseline. Models with only a $q$ or $v$ term are compared to $(0,1)$. The Wald statistic thus provides a test of whether higher-order terms are jointly significant 
relative to the comparable first-order $(1,0),(0,1)$ or $(1,1)$ model. Note that a significant Wald statistic in a second-order model will generally result in a significant Wald statistic in similar third-order models because all higher-order terms are compared to a first-order base.

Table 4 a reports $L M_{4}$, joint bias and Wald tests for the various $\operatorname{VARMA}(1,1)$-EGARCH$(p, q)$ candidate models and market pairs. Table $4 \mathrm{~b}$ reports $p$-values for these diagnostic statistics. Some general conclusions are apparent from the tables. First, diagnostic statistics tend toward insignificance at higher lags in each series. Also, at least one lagged volatility term is necessary to introduce persistence into estimates of conditional volatility, as specifications from $(0,0)$ to $(0,3)$ are poorly behaved across all four series. $\operatorname{EGARCH}(1,0),(2,0)$, or $(3,0)$ are not considered, as these models reduce to a constant-variance model.

$\operatorname{EGARCH}(1,1)$ works well for the U.K. and U.S. series in tables $4 \mathrm{a}$ and $4 \mathrm{~b}$, rendering the diagnostic tests insignificant in these series. Wald tests for joint significance in the higher-order terms for the U.K. and U.S. series are significant, but the other diagnostic tests show that $\operatorname{EGARCH}(1,1)$ is sufficient to accommodate the observed volatility persistence in these series. ${ }^{2}$

Higher-order terms are necessary for Japan, where the $L M_{4}$ statistics indicate $\mathrm{ARCH}(4)$ disturbances in the residuals of the $\operatorname{EGARCH}(1,1)$ model. Lags of at least $(1,3)$ or $(2,2)$ are necessary to remove significance in the $\mathrm{LM}_{4}$ statistics. $\operatorname{EGARCH}(2,2)$ is adopted as the parsimonious model for Japan, although $(1,3)$ works as well. The significant Wald statistics for Japan confirm that the higher-order terms are jointly significant.

Tables $4 \mathrm{a}$ and $4 \mathrm{~b}$ also suggest that a higher-order EGARCH term can improve the fit of the Emu series. In particular, lags of $(1,2)$ or $(2,1)$ or higher are necessary to remove significance in the $L M_{4}$ statistics. Whether the second-order lag is on previous volatility or innovation does not seem to matter. Note that higher-order lags cannot remove the significance in the joint bias statistics for the Emu, although $\operatorname{EGARCH}(0, q)$ models with $q \geq 1$ do improve the behavior of the squared normalized residuals. Choice of the best model for this series is difficult, as the Wald statistic is significant for the $\operatorname{EGARCH}(2,1)$ specification, but not for the $\operatorname{EGARCH}(1,2)$ specification. The next section assesses whether $\operatorname{EGARCH}(2,1)$ can improve on $\operatorname{EGARCH}(1,1)$

2. Diagnostic $p$-values that exceed 0.95 for the U.S. $\operatorname{EGARCH}(0,2)$ and $\operatorname{EGARCH}(2,2)$ models merely indicate that residual autocorrelations are smaller than normal, and hence benign. 


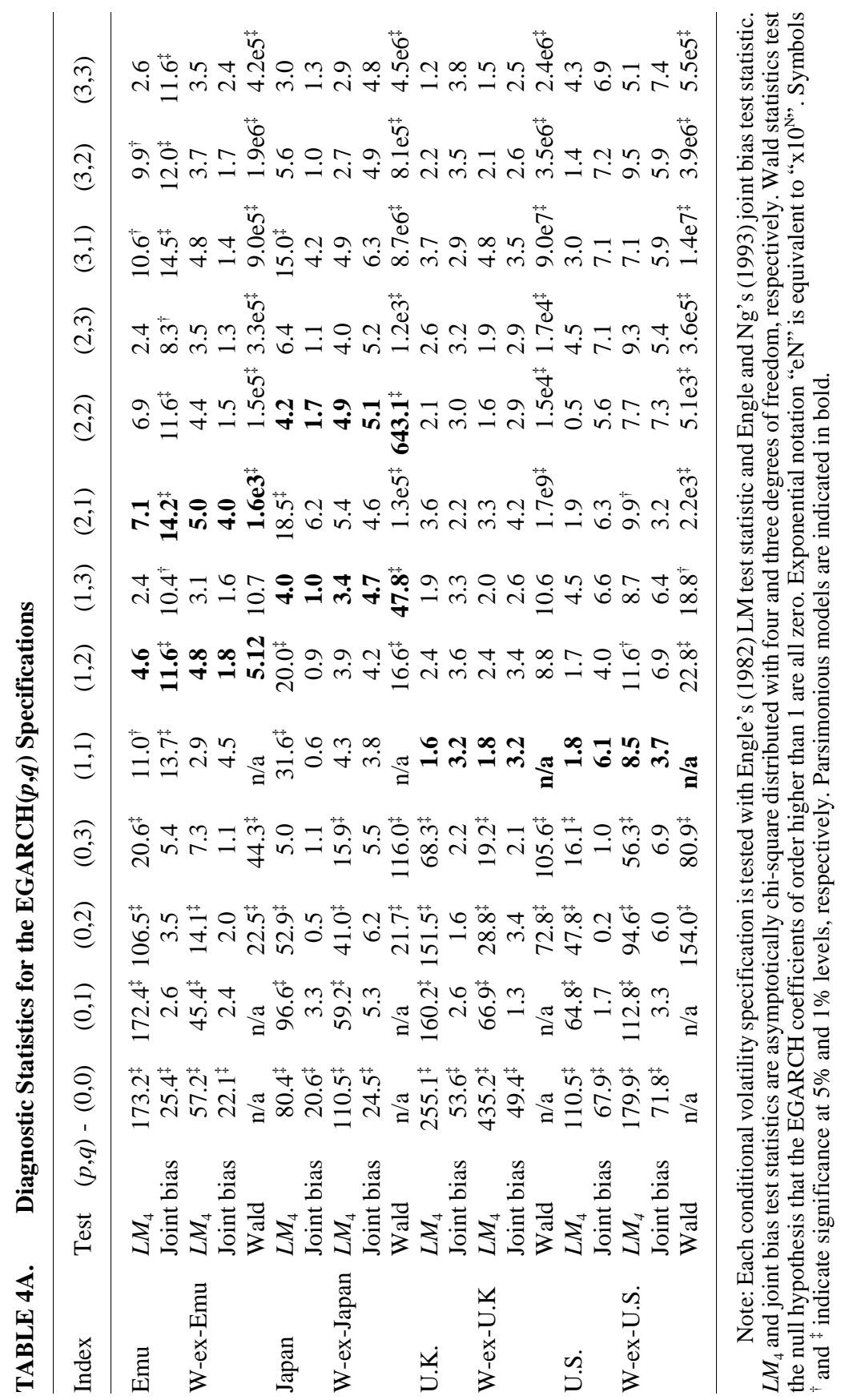




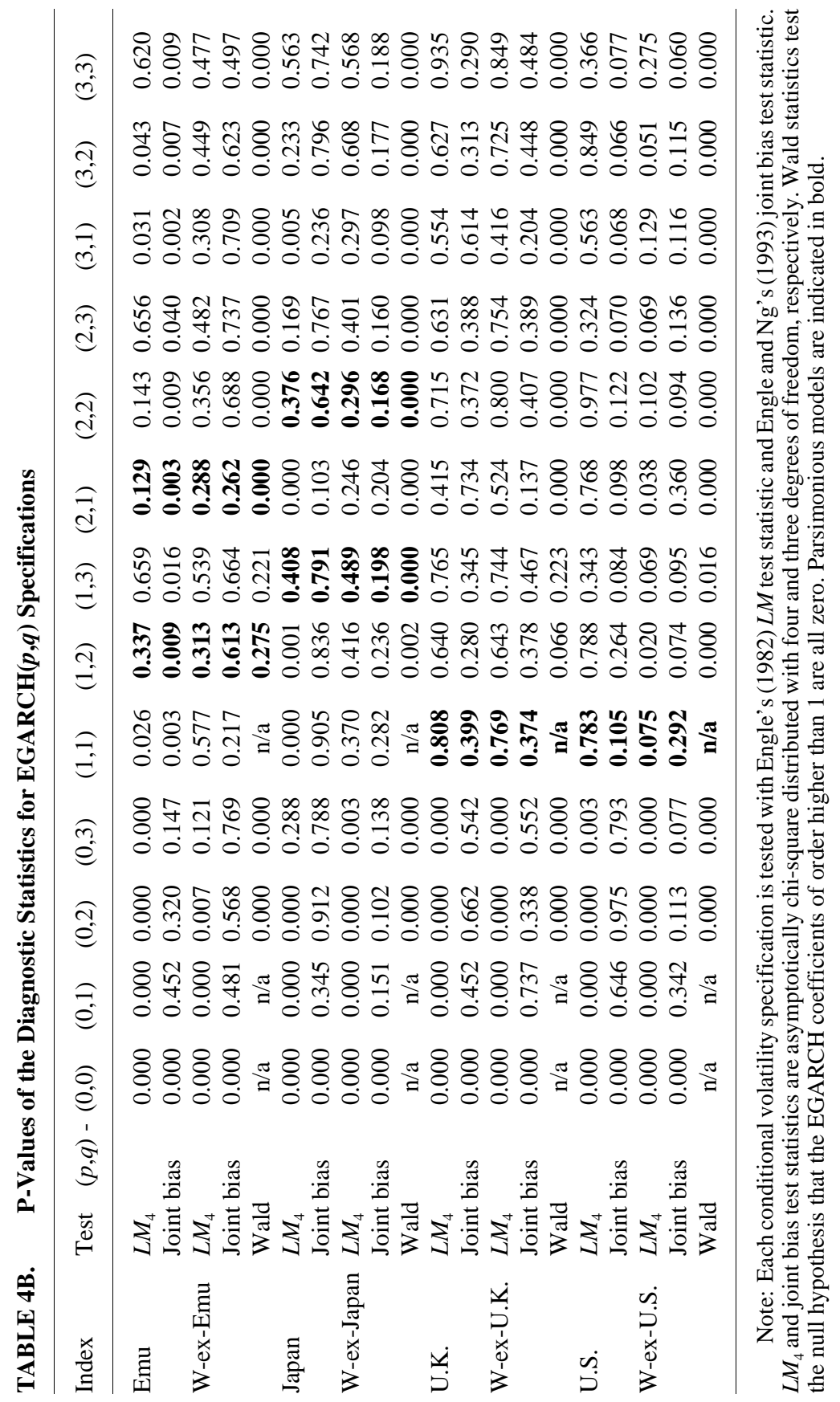




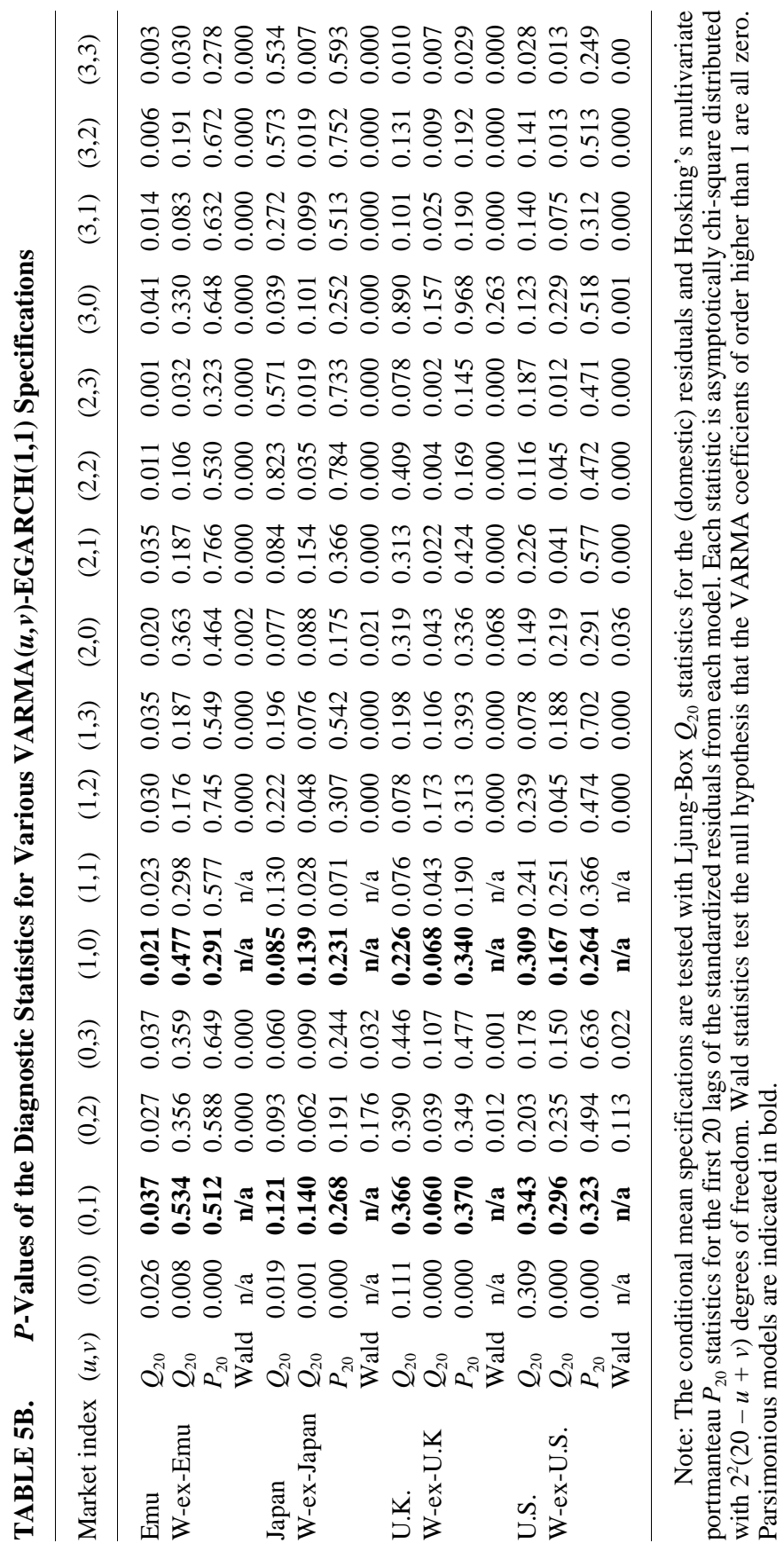




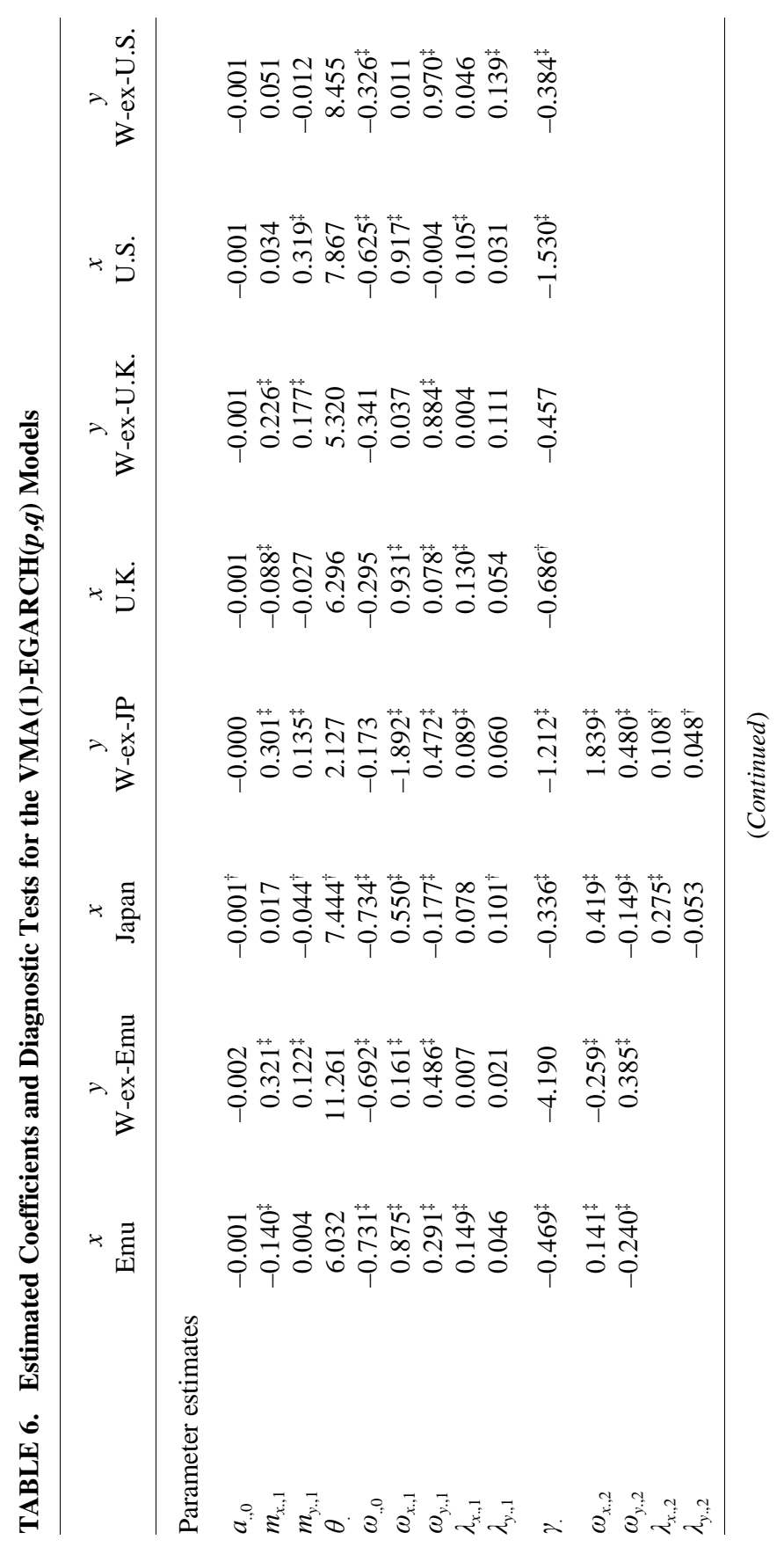




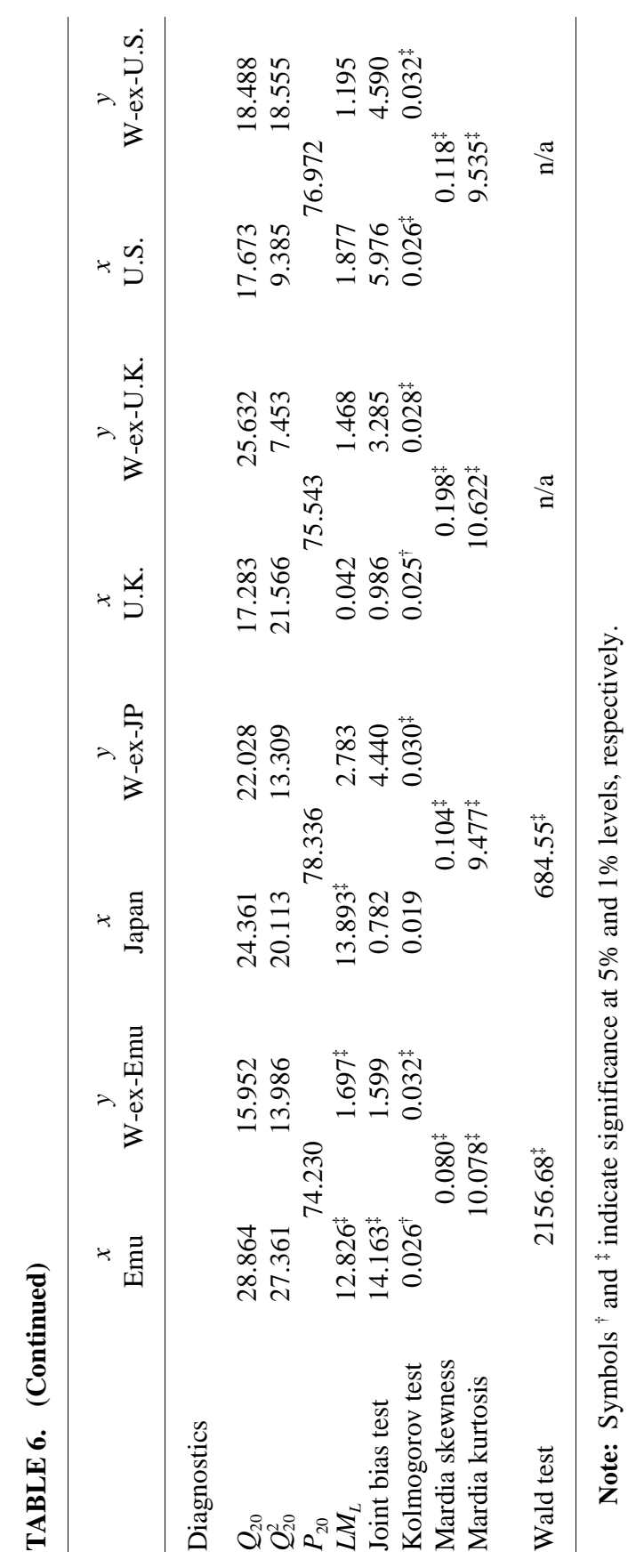


for the Emu series. This model is chosen rather than $\operatorname{EGARCH}(1,2)$ because of its significant Wald statistic in table 4a.

Tables $5 \mathrm{a}$ and $5 \mathrm{~b}$ report $Q_{20}, P_{20}$ and Wald statistics for the various $\operatorname{VARMA}(u, v)$ conditional mean models. The main conclusion here is that $\operatorname{VAR}(1)$ and $\operatorname{VMA}(1)$ are equally capable of removing intertemporal dependencies from the residuals. Indeed, diagnostic statistics and their $p$-values are nearly identical across all four series for these two specifications. Some conditional mean specification is necessary, as the VARMA $(0,0)$ specification is a poor fit for each series. A VMA(1) conditional mean specification is adopted following Burns, Engle and Mezrich (1998), although VAR(1) works as well. The final, parsimonious models have a VMA(1) conditional mean and a conditional volatility specification of $\operatorname{EGARCH}(2,1)$ for the Emu, $\operatorname{EGARCH}(2,2)$ for Japan, and $\operatorname{EGARCH}(1,1)$ for the United Kingdom and the United States.

\section{A Parsimonious Model of Bivariate Returns to International Stock Indices}

Table 6 shows parameter estimates and diagnostic statistics for the best-fitting VMA(1)-EGARCH( $(p, q)$ model for each series. With the exception of Japan, the constant coefficients $a_{x, 0}$ and $a_{y, 0}$ are not statistically significant, so these typically do not show a trend over the sample period. The $\theta$. terms also are not significant, so the level of return is not related to volatility except through the conditional volatility specification. This is consistent with most previous estimates of ARCH-in-mean effects.

These indices exhibit predominantly positive moving average terms in table 6. The strongest effects are in the serial cross terms $m_{x y, 1}$ and $m_{y x, 1}$, which are positive and significant whenever one index closes before another. For example, positive and significant $m_{x y, 1}$ terms for the domestic Emu (0.319), Japan (0.301), and U.K. (0.226) indices reflect information from world-ex-domestic markets (such as the U.S.) that arrives after the close of the domestic market and is included in the next day's domestic return. Similarly, the positive and significant cross effect $m_{y x, 1}$ for the U.S. series (0.319) arises because world-ex-U.S. returns include information from the previous day's U.S. return. There are also positive and significant moving average terms $m_{y y, 1}$ for the world-ex-Emu (0.101), world-ex-Japan (0.135) and world-ex-U.K. (0.177) indices. 
The negative and significant moving average terms in the Emu $(-0.137)$ and U.K. (-0.088) appear at odds with the other moving average terms. However, the sum $m_{x x, 1}+m_{x y, 1}$ is positive for the Emu (0.182), Japan (0.318), the U.K. (0.138), and the U.S. (0.085), so the combined effect of serial and serial cross terms on domestic return is positive for each domestic index.

The indices exhibit strong volatility persistence. All eight $\omega_{x x, 1}$ and $\omega_{y y, 1}$ terms on lagged log variances are positive and significant. The $\omega_{x x, 1}$ terms are close to unity for the first-order terms of the U.K. (0.931) and U.S. (0.917) indices. Similarly, the $\omega_{y y, 1}$ terms are close to unity for the first-order terms of the world-ex-U.K. (0.884) and world-ex-U.S. (0.970) indices.

In the Emu, the effect is spread over two lags and often appears in the cross effects. Each of the first-order autoregressive volatility terms $w_{x x, 1}$ and $w_{y y, 1}$ are positive and significant, but the sums $\left(\omega_{x x, 1}+\omega_{x x, 2}\right)=$ 0.548 and $\left(\omega_{y y, 1}+\omega_{y y, 2}\right)=0.750$ are not as close to unity as in the other series. The world-ex-Emu index also has a positive and significant second-order $\omega_{y y, 2}$ term. Positive and significant cross effects $\omega_{x y, 1}=$ 0.744 and $\omega_{y x, 1}=0.125$ are not a surprise, as Emu markets close after Japan and before the U.S. Second-order cross effects are not significant.

Similarly, in Japan the sums $\left(\omega_{x x, 1}+\omega_{x x, 2}\right)=0.969$ and $\left(\omega_{y y, 1}+\omega_{y y, 2}\right)$ $=0.952$ are close to unity. The cross effects $\omega_{x y, 1}$ and $\omega_{x y, 2}$ have nearly the same absolute value but opposite sign, so the $\omega_{x y, 1}=-1.892 \mathrm{impact}$ of volatility in Japan on world-ex-Japan volatility at lag one is canceled out by the cross effect $\omega_{x y, 2}=-1.839$ at lag two. The impact of world-ex-Japan volatility on Japanese volatility is negative and significant at lags one $\left(\omega_{y x, 1}=-0.177\right)$ and two $\left(\omega_{y x, 2}=-0.149\right)$, although the magnitude of this cross effect is far less than the $\left(\omega_{x x, 1}+\omega_{x x, 2}\right)=$ 0.969 magnitude of the serial effect within the domestic Japan index.

The $\gamma$. coefficients are negative and mostly significant, so the positive $\lambda$ terms mean that conditional variances are larger when previous innovations are negative than when they are positive. This is a common finding in many asset prices, including international stock indices (Kroner and $\mathrm{Ng}$ [1998]). The $\lambda_{x x, 1}$ and $\lambda_{y y, 1}$ terms are positive, and generally significant for the first-order models of the U.K. (0.130), and the U.S. (0.105 and 0.139), so negative innovations in each index have a larger influence on conditional variance than positive innovations. There is mixed evidence of asymmetric volatility traveling between the indices in the first-order models of the Emu, U.K., and U.S., with a single positive and significant cross effect $\lambda_{y x, 1}$ for world-ex-Emu 
innovations on Emu returns.

For Japan's EGARCH $(2,2)$ model, positive and significant $\lambda_{x x, 2}$ and $\lambda_{y y, 2}$ terms appear at lag two but not at lag one. In contrast to the U.K. and U.S. series, three of the four cross effects $\left(\lambda_{x y, 1}=0.089, \lambda_{y x, 1}=0.101\right.$, and $\left.\lambda_{x y, 2}=0.108\right)$ are positive and significant in the Japan series. The other cross effect $\left(\lambda_{y x, 2}=-0.053\right)$ is not significant. As in the other series, conditional variances are larger when previous innovations are negative than when they are positive. However, the relation travels both within and across indices and continues for two lags in the Japan series.

Overall, the diagnostics tests in table 6 indicate that an VMA(1)-EGARCH(1,1) model captures most of the characteristics of the U.K. and U.S. series. Diagnostic statistics for the Emu's $\operatorname{VMA}(1)-\operatorname{EGARCH}(2,1)$ model and Japan's VMA(1)-EGARCH(2,2) model are slightly more problematic. All of the test statistics should be insignificant if a model is well specified. Ljung-Box $Q_{20}$ statistics on standardized VMA(1) residuals are insignificant for each index. Each bivariate series passes Hosking's portmanteau test $P_{20}$ of the VMA(1) conditional mean specification. $Q_{20}^{2}$ tests on squared standardized VMA(1) residuals and $L M_{L}$ tests for $\mathrm{ARCH}(L)$ disturbances reveal no problems, with the exception of the $L M_{3}$ test for Japan. The domestic Emu index is the only one that fails the joint bias test. The world-ex-domestic residuals and the bivariate residuals are unable to pass the normality tests at a one percent significance level, suggesting that an alternative error distribution might be worth exploring.

In summary, a first-order vector autoregressive or moving average process is sufficient to model conditional mean returns in these international stock indices. Although first-order conditional volatility terms are sufficient in two of the four series, second-order terms are significant in the bivariate Emu and Japan series. Robust Wald statistics on the second-order terms are significant relative to the $\operatorname{EGARCH}(1,1)$ baseline, and residuals are poorly behaved without the second-order terms. Finally, the univariate and the bivariate series generally have a negative and significant asymmetric volatility term in the EGARCH model, indicating a greater volatility response to negative innovations than to positive innovations.

\section{Conclusions and Suggestions for Future Research}

This article documents the stochastic properties of bivariate returns to MSCI's domestic and world-ex-domestic stock index pairs for the Emu, 
Japan, the United Kingdom, and the United States. Bivariate returns to these series are important because they determine the diversification gains to domestic investors from international equity investments. A search is conducted for higher-order terms in the class of bivariate $\operatorname{VARMA}(u, v)$-EGARCH$(p, q)$ models with a constant conditional correlation and normally distributed errors.

Higher-order conditional volatility terms can be significant in these data. A VMA(1)-EGARCH(1,1) model provides a relatively good fit for the U.K. and U.S. series. However, higher-order EGARCH terms and robust Wald statistics are significant in the Emu and Japan. This is similar to the proportion of significant higher-order terms in the univariate series.

This study could be extended in many ways, as findings are limited by the assumptions and data. For example, it may be fruitful to investigate alternative conditional correlation structures or error distributions, as Bollerslev, Engle and Wooldridge (1988) and King, Sentana and Wadhwani (1994) find that stock index correlations vary over time with higher correlations in bear markets (Longin and Solnik [2001]; Butler and Joaquin [2002]; Bae, Karolyi and Stulz [2003]). Nonnormal error distributions might prove useful (Liesenfeld and Jung [2000]), such as the skewed generalized $T$ (Theodossiou [1998]), stable paretian (Mittnik, Paolella and Rachev [2002]), exponential generalized beta (Wang, et. al. [2001]), or generalized error distribution (Nelson [1988]). Also, higher-order conditional volatility lags could be investigated in bivariate series that involve higher transaction costs, more price adjustment delays, or lower liquidity than the large markets examined in this study.

Although the statistical significance of higher-order conditional volatility terms is demonstrated in this study, their economic significance is not. The economic significance of a more precise model of conditional volatility is a potentially fruitful area of research and is receiving increasing attention in the literature. For example, Fleming, Kirby and Ostdiek $(2001,2003)$ assess whether an improved volatility model can lead to better asset allocation decisions and estimate that a first-order model of conditional volatility is worth 50 to 200 basis points per year to a risk-averse investor relative to an unconditional volatility model. The economic significance of higher-order conditional volatility terms could be assessed in a similar manner. 


\section{References}

El Babsiri, M., and Zakoian, J. 2001. Contemporaneous asymmetry in GARCH processes. Journal of Econometrics 101 (2): 257-294.

Bae, K.; Karolyi, G. A.; and Stulz, R.M. 2003. A new approach to measuring financial market contagion. Review of Financial Studies 16 (3): 717-763.

Baillie, R.T.; Cecen, A.A.; and Han, Y. 2000. High frequency Deutsche mark-US dollar returns: FIGARCH representations and nonlinearities. Multinational Finance Journal 4 (3/4): 247-267.

Black, F. 1976. Studies in stock price volatility changes. Proceedings of the 1976 Business Meeting of the Business and Economic Statistics Section of the American Statistical Association: 177-181.

Bollerslev, T. 1990. Modelling the coherence in short-run nominal exchange rates: A multivariate generalized ARCH approach. Review of Economics and Statistics 72 (3): 498-505.

Bollerslev, T.; Engle, R.F.; and Wooldridge, J.M. 1988. A capital asset pricing model with time-varying covariances. Journal of Political Economy 96: 116-131.

Bollerslev T., and Mikkelsen, H.O. 1996. Modeling and pricing long memory in stock market volatility. Journal of Econometrics 73: 151-184.

Booth, G.G.; Martikainen, T; and Tse, Y. 1997. Price and volatility spillovers in Scandinavian stock markets. Journal of Banking \& Finance 21 (6): 811-823.

Burns, P.; Engle, R.F.; and Mezrich, J. 1998. Correlations and volatilities of asynchronous data. Journal of Derivatives 5 (Summer): 7-18.

Butler, K.C., and Joaquin, D.C. 2002. Are the gains from international portfolio diversification exaggerated? The influence of downside risk in bear markets. Journal of International Money and Finance 21 (7): 981-1011.

Cao, C.Q., and Tsay, R.S. 1992. Nonlinear time-series analysis of stock volatilities. Journal of Applied Econometrics 7: S165-S185.

Chen, Y., and Kuan, C. 2002. Time irreversibility and EGARCH effects in US stock index returns. Journal of Applied Econometrics 17 (5): 565-578.

Cheung, Y., and Fung, H. 1997. Information flows between Eurodollar spot and futures markets. Multinational Finance Journal 1 (4): 255-271.

Cheung, Y., and Ng, L. K. 1992. Stock price dynamics and firm size: An empirical investigation. Journal of Finance 47 (5): 1985-1997.

Chong, C.W.; Ahmad, M.I.; and Abdullah, M.Y. 1999. Performance of GARCH models in forecasting stock market volatility. Journal of Forecasting 18 (5): 333-343.

Christie, A.A. 1982. The stochastic behavior of common stock variances: Value, leverage and interest rate effects. Journal of Financial Economics 10: 407-432.

Christofi, A., and Pericli, A. 1999. Correlation in price changes and volatility of major Latin American stock markets. Journal of Multinational Financial 
Management 9 (1): 79-93.

Daouk, H., and Guo, J.Q. 2004. Switching asymmetric GARCH and options on a volatility index. Journal of Futures Markets 24 (5): 251-282.

Day, T.E., and Lewis, C.M. 1992. Stock market volatility and the information content of stock index options. Journal of Econometrics 52 (1-2): 267-287.

Engle, R.F. 1982. Autoregressive conditional heteroscedasticity with estimates of the variance of United Kingdom inflation. Econometrica 50 (4): 987-1007.

Engle, R.F. 1993. Statistical models for financial volatility. Finance Analysts Journal 49 (1): 72-78.

Engle, R.F., and Ng, V.K. 1993. Measuring and testing the impact of news on volatility. Journal of Finance 48: 1749-1778.

Fleming, J.; Kirby, C.; and Ostdiek, B. 2001. The economic value of volatility timing. Journal of Finance 56 (1): 329-352.

Fleming, J.; Kirby, C.; and Ostdiek, B. 2003. The economic value of volatility timing using 'realized' volatility. Journal of Financial Economics 67 (3): 473-509.

Fornari, F., and Mele, A. 1997. Sign- and volatility-switching Arch models: Theory and applications to international stock markets. Journal of Applied Econometrics 12 (1): 49-65.

French, K, and Roll, R.R. 1986. Stock return variances: The arrival of information and the reaction of traders. Journal of Financial Economics 17 (1): 5-26.

Glosten, L.R.; Jagannathan, R.; and Runkle, D.E. 1993. On the relation between the expected value and the volatility of the nominal excess return on stocks. Journal of Finance 48 (5): 1779-1801.

Hamilton, J.D. 1989. A new approach to the economic analysis of nonstationary time series and the business cycle. Econometrica 57: 357-384.

He, C., and Teräsvirta, T. 1999. Properties of moments of a family of GARCH processes. Journal of Econometrics 92 (1): 173-192.

He, C.; Teräsvirta, T.; and Malmsten, H. 2002. Moment structure of a family of first-order exponential GARCH models. Econometric Theory 18 (4): 868-885.

Hentschel, L. 1995. All in the family: Nesting symmetric and asymmetric GARCH models. Journal of Financial Economics 39 (1): 71-104.

Hirshleifer, D. 2001. Investor psychology and asset pricing. Journal of Finance 56 (4): 1533-1597.

Hosking, J.R.M. 1980. The multivariate portmanteau statistic. Journal of the American Statistical Association 75: 602-608.

Jacobs, M., and Onochie, J. 1998. A bivariate generalized autoregressive conditional heteroscedasticity-in-mean study of the relationship between return variability and trading volume in international futures markets. Journal of Futures Markets 18: 379-397.

Kassimatis, K. 2002. Financial liberalization and stock market volatility in 
selected developing countries. Applied Financial Economics 12 (6): 389-394.

Kim, D., and Kon, S.J. 1994. Alternative models for the conditional heteroscedasticity of stock returns. Journal of Business 67 (4): 563-595.

Koutmos, G. 1996. Modeling the dynamic interdependence of major European stock markets. Journal of Business Finance and Accounting 23 (7): 975-988.

Koutmos, G. 2000. Dynamic interactions between stock and foreign exchange markets. Global Business and Economics Review 2 (2): 143-58.

Koutmos, G.; Negakis, C.; and Theodossiou, P. 1993. Stochastic behaviour of the Athens stock exchange. Applied Financial Economics 3 (2): 119-126.

Kroner, K.F., and Ng, V.K. 1998. Modeling asymmetric comovements of asset returns. Review of Financial Studies 11: 817-844.

Liesenfeld, R., and Jung, R.C. 2000. Stochastic volatility models: Conditional normality versus heavy-tailed distributions. Journal of Applied Econometrics 15: 137-160.

Ljung, G.M., and Box, G.E.P. 1978. On a measure of lack of fit in time series models. Biometrika 65: 297-303.

Lo, A., and MacKinlay, C. 1990. An econometric analysis of nonsynchronous trading. Journal of Econometrics 45: 181-211.

Lobo, B.J. 2000. Asymmetric effects of interest rate changes on stock prices. Finance Review 35 (3): 125-144.

Longin, F., and Solnik, B. 2001. Extreme correlation of international equity markets. Journal of Finance 56: 649-676.

Mittnik, S.; Paolella, M.S.; and Rachev, S.T. 2002. Stationarity of stable power-GARCH processes. Journal of Econometrics 106 (1): 97-107.

Nelson, D.B. 1988. The time series behavior of stock market volatility and returns. Massachusetts Institute of Technology, Unpublished $\mathrm{PhD}$ dissertation.

Nelson, D.B. 1991. Conditional heteroskedasticity in asset returns: a new approach. Econometrica 59 (2): 347-370.

Niarchos, N.; Tse, Y.; Wu, C.; and Young, A. 1999. International transmission of information: A study of the relationship between the U.S. and Greek stock markets. Multinational Finance Journal 3 (1): 19-40.

Pagan, A.R. and Schwert, G.W. 1990. Alternative models for conditional stock volatility. Journal of Econometrics 45 (1-2): 267-290.

Rabemananjara, R., and Zakoian, J.M. 1993. Threshold ARCH models and asymmetries in volatility. Journal of Applied Econometrics 8 (1): 31-49.

Theodossiou, P. 1998. Financial data and the skewed generalized T distribution. Management Science 44 (12): 1650-1661.

Tse, Y. 1998. International transmission of information: Evidence from the Euroyen and Eurodollar futures markets. Journal of International Money and Finance 17 (6): 909-929.

Tse, Y., and Booth, G.G. 1996. Common volatility and volatility spillovers 
between US and Eurodollar interest rates Evidence from the futures market. Journal of Economics and Business 48 (3): 299-313.

Wald, A. 1943. Tests of statistical hypotheses concerning several parameters when the number of observations is large. Transactions of the American Mathematical Society 54: 426-482.

Wang, K.; Fawson, C.; Barrett, C.B.; and McDonald, J.B. 2001. A flexible parametric GARCH model with an application to exchange rates. Journal of Applied Econometrics 16 (4): 521-536.

White, H. 1982. Maximum likelihood estimation of misspecified models. Econometrica 50: 1-25.

Wu, G. 2001. The determinants of asymmetric volatility. Review of Financial Studies 14 (3): 837-839. 